\title{
RESENHA
}

\section{Se Deus fosse um ativista dos direitos humanos}

Allisson Goes ${ }^{1}$

Boaventura de Santos Santos é um sociólogo português nascido em 1940 na cidade de Coimbra. Doutorou-se em Sociologia do Direito na Universidade de Yale, tendo atuado em universidades como Coimbra, Winsconsin, Warwick e Londres. Atualmente é diretor do Centro de Estudos Sociais da Universidade de Coimbra (CES/UC) e Coordenador do Observatório Permanente da Justiça Portuguesa. Entre muitos temas, suas obras estão no âmbito da sociologia do direito, teoria sociológica, direitos humanos, globalização e teoria pós-colonial.

O livro "Se Deus fosse um ativista dos direitos humanos" publicado em Portugal em 2013, chegou ao Brasil no ano seguinte. A obra dá conta do movimento contemporâneo de oposição às ideias de autonomia individual oportunizadas pelos mercados, sejam locais, nacionais ou globais. Tais ideias, de autonomias individuais, fizeram emergir, segundo o autor, um ser associal ou antissocial, o homo sociologicus do capitalismo. Ora, se por um lado temos a manifestação da autonomia e individualismo, por outro, surgem duas propostas que colidem com essas ideias: os direitos humanos e as teologias políticas. As duas políticas normativas têm uma presença desigual nas diferentes partes do mundo, mas pretendem ser globais. Ao lado dos direitos humanos surgiram as teologias políticas que pretendem uma maior ou menor atuação da religião na esfera pública. Ao longo da obra o autor aponta a diversidade dessas teologias, deixando claro que não se trata de um pensamento unitário. Santos modela sua obra a partir da confluência entre direitos humanos e teologias políticas, o que chama de zonas de

\footnotetext{
${ }^{1}$ Mestre e Doutorando em Sociologia (PPGS/UFS). Pesquisador do Grupo de Estudos e Pesquisa Processos Identitários e Poder. E-mail: allissongoes@gmail.com.
} 
contato, como geradora de novas ideias que permitam uma transformação social radical e progressista (p. 12).

$\mathrm{Na}$ introdução do livro, o autor concentra-se na questão dos direitos humanos como portador de uma frágil hegemonia. Como código universal da dignidade humana, a maior parte da população vive apenas de discursos de direitos humanos, ou seja, vivem numa situação de negação desses mesmos direitos. Sendo um discurso hegemônico, pergunta o autor, é possível que os grupos sociais penalizados utilizem desse mesmo discurso hegemônico para subverter a lógica da exclusão e do sofrimento? A primeira coisa é suspeitar da concepção de direitos humanos convencionalmente defendidos e com origem numa matriz ocidental e liberal. Se os direitos humanos, enquanto discurso de emancipação foram concebidos para vigorar apenas nas sociedades metropolitanas, Santos afirma que o direito e os direitos têm uma base revolucionária, tendo como exemplo as revoluções francesa e americanas.

Contudo, há algumas ilusões sobre o consenso em relação aos direitos humanos. Santos aponta quatro delas: a teleológica, o triunfalismo, a descontextualização e o monopolitismo (p. 18). A ilusão teleológica considera que a história é linear e que chegamos a esta concepção de direitos humanos a partir de um percurso acumulativo sem considerar a contingência dos fatos histórico e da concorrência entre distintas visões de dignidade humana em diferentes épocas. A segunda ilusão, o triunfalismo, afirma a superioridade dos direitos humanos em relação a outras propostas relativas à dignidade humana, o que precisa ser ainda provado. Como terceira ilusão Santos aponta a descontextualização, ou seja, é preciso entender que os direitos humanos foram utilizados e entendidos de maneiras diferentes em contextos históricos diferentes, estes foram objetos tanto de avanços revolucionários, como de contrarrevoluções. Por fim, o sociólogo aponta o monolitismo como quarta ilusão e que reside na negação ou minimização das tensões e contradições no interior das teorias dos direitos humanos.

Diante dessas ilusões, os direitos humanos apresentam-se com princípios diferentes sobre dignidade e justiça social, apesar de existir uma única humanidade. Como apreender tal diversidade e o que fazer com ela? Não se trata de reconhecer a diversidade a partir da permanência da universalidade dos direitos humanos, diz o autor, mas considerar movimentos contra-hegemônico que não se alinham aos

\section{Revista Ambivalências}

V.4 4 N.8 • p. $311-318 \cdot$ Jul-Dez/2016

ISSN 2318-3888 • DOI: 10.21665/2318-3888.v4n8p311-318 
direitos humanos ocidentais, como formuladores de princípios de dignidade humana, tais como os movimentos indígenas na América Latina, os movimentos camponeses na África e na Ásia e a insurgência islâmica, diferentes entre si, mas com pretensões de resistência ao Ocidente. Nessa obra, Santos trata particularmente dos movimentos de resistência que advogam a presença da religião na esfera pública e seu confronto com os direitos humanos. Pode-se encontrar neste ponto uma rivalidade e até mesmo uma contradição.

No primeiro capítulo o sociólogo trata da globalização das teologias políticas que ganham relevância e capilaridade em nível transnacional. Antes, o autor distingue o que são ideias hegemônicas, contrahegemônicas e não hegemônicas relacionadas à globalização. São hegemônicas uma rede de relações econômicas, políticas, culturais e epistemológicas baseadas no capitalismo, no patriarcalismo e no colonialismo que se legitimam ou dissimulam uma legitimidade a partir do primado do direito, da democracia e dos direitos humanos. Uma observação importante recai sobre as ideias hegemônicas: o que é hegemônico na globalização não é global. Em termos de contrahegemonia, temos todos os movimentos que concebem estruturas para fornecer alternativas possíveis ao que é posto pelo que é hegemônico, essas articulações são feitas por ONG's, Fóruns e Movimentos Sociais diversos. Por fim, o não-hegemônico vai de encontro ao hegemônico para substituí-lo por novas formas de opressão (p. 31-34).

Ainda neste capítulo, Santos aponta uma tipologia das teologias políticas, sendo estas modos de conceber a intervenção da religião na organização política e social da sociedade. Das radicais às progressistas, todas reivindicam uma intervenção na esfera pública a partir da mensagem divina com críticas a distinção entre as duas esferas, pública e privada e ao indivíduo do iluminismo. Nota-se aqui um ponto bastante interessante que está numa possível ruptura da hegemonia dos direitos humanos como única gramática possível referente à dignidade humana. É claro que estamos falando das teologias políticas progressistas, uma delas a chamada teologia intercultural defendida pelo autor, apresentase como crítica à globalização neoliberal e a primazia do conhecimento científico-técnico ocidental.

Um fato curioso é esclarecido pelo autor, o de que o fundamentalismo nasceu nos Estados Unidos no século XX (p. 40), o que parece 
surpreendente já que associamos o fundamentalismo ao islamismo e práticas religiosas islâmicas. Para Santos, o fundamentalismo nasceu nos Estados Unidos sob a forma do fundamentalismo cristão, basicamente protestante.

É nos capítulos 2 e 3 que o autor traça um panorama dos fundamentalismos islâmico e cristão, como ideias não hegemônicas que pretendem, ao nosso ver, serem globais. O fundamentalismo islâmico advoga que a lei divina ou shari'a deve ser a base de toda sociedade e de toda vida pública dos crentes (p. 58). Está claro que temos aqui uma oposição a organização da sociedade em Estados nacionais que, inclusive, fracassaram como modo de organização nas sociedades islâmicas. Esse fracasso, diz Santos, é o alimento para o Islã político que substitui o Estado por uma organização transnacional de fiéis.

Em se tratando do fundamentalismo cristão sua crítica recai sobre a liberalização da sociedade em questões como aborto, família e educação. Ainda, é possível identificar este tipo de fundamentalismo na teologia da prosperidade que cultua o capitalismo e reitera a legitimação divina da riqueza e do enriquecimento (p. 73). Sendo Deus o regulador da prosperidade não cabe no capitalismo um Estado de bem-estar social, este último pode levar aos indivíduos à preguiça, advoga o fundamentalismo cristão. No final do terceiro capítulo identificamos as correntes neopentecostais que indicam somente um caminho para lidar com a interface entre religião e sociedade, ou seja, sem levar em consideração os contextos sociais específicos que podem levar a uma evangelização pura e dura (p. 76-77).

Os dois tipos de fundamentalismo têm como intenção permear a organização social e política da sociedade. Ou seja, mesmo se tratando de fundamentalismos não significa que seus integrantes rejeitem a participação social e política, ao contrário, eles se utilizam de elementos, como se associarem a diversos governos, para alterar as agendas sociais já constituídas.

Após abordar as teologias políticas e os fundamentalismos Santos propõe uma análise das zonas de contato entre os direitos humanos e as teologias políticas, objeto do capítulo 4. Entende-se por zonas de contato os "campos sociais em que diferentes mundos da vida cultural se encontram, medeiam, negociam e confrontam" ou ainda "zonas em que ideias, conhecimentos, formas de poder, universos simbólicos e modos 
de agir rivais se encontram em condições desiguais e interagem de múltiplas formas (resistência, rejeição, assimilação, imitação, tradução, subversão etc.) de modo a dar origem a constelações culturais híbridas, nas quais a desigualdade das trocas pode ser reforçada ou reduzida" ( $p$. 81). Interessante notar que essas zonas de contato subsidiam o que o autor chamou de teologia intercultural, como também na defesa da interculturalidade posta como elemento para consolidar uma nova gramática para os direitos humanos.

Assim, as zonas de contato não significam interações harmônica, ou seja, há uma série de tensões oriundas do abismo entre discurso e práticas relativos aos direitos humanos. O colonialismo, arma pela qual a modernidade ocidental penetrou as sociedades não-ocidentais fez com que muitos povos se insurgissem, dentre os quais destacam-se os povos islâmicos. Para estes, essa submissão apresenta-se como uma derrota efetiva (p. 86). Uma outra tensão ou turbulência concentra-se na disputa entre o pensamento de raízes e o das opções. Sendo o de raízes tudo que é singular, único e que dá segurança, ao contrário do de opções que é efêmero e indeterminado. Essa equação é validada a partir de duas astúcias, a astúcia entre passado e futuro e a astúcia do equilíbrio entre raízes e opção. A primeira afirma que tanto "o pensamento das raízes como o das opções são pensamentos do futuro" (p. 89), isto quer dizer que o pensamento de raiz tem muito de projeção para o futuro, o que parece ser negado pelos que optaram por ele. Na segunda astúcia, Santos diz que esse equilíbrio não é bem como parece ao ser apresentado, visto que, o que impera são as opções nas diversas sociedades.

Para encerrar a discussão da turbulência entre raízes e opções o autor propõe uma série de afinidades entre a globalização neoliberal e as teologias fundamentalistas, algo que parece-nos, a princípio, incompatível. Para tanto, o autor, em primeiro lugar, a modernidade ocidental radicalizou as opções, "libertando os povos do constrangimento das raízes" (p. 92), quando na verdade, frisa Santos, essa autonomia abstrata a que foi relegada a vários povos e grupos sociais diminui a capacidade concreta de optar. É o exemplo dos desempregados, imigrantes, famílias empobrecidas etc. Em segundo lugar, sociedades colonizadas como as sociedades islâmicas estão radicalizando as raízes, sendo a única alternativa buscar uma raiz fundadora. Apesar das diferenças da turbulência entre raízes e opções nas sociedades ocidentais e islâmicas, o sociólogo aponta algumas 
semelhanças entre elas: o medo do futuro; e a polarização entre processos autoritários de despolitização e de repolitização conducente à instrumentalização de questões de princípio, ou seja, a reafirmação das questões de princípios baseadas na religião, muito fortemente encontrada nas sociedades islâmicas ao reforçar a shari'a como princípio condutor da sociedade (p. 99).

A essa altura Santos pergunta: são possíveis outros direitos humanos? O sociólogo acredita que há "um enorme potencial para a tradução intercultural entre os direitos humanos reconstruídos e as teologias políticas progressistas plurais - sejam elas cristãs, islâmicas ou outras". Assim, o quinto e último capítulo concentra-se na formulação de uma concepção pós-secularista de direitos humanos baseada no contato entre direitos humanos contra-hegemônicos e teologias políticas progressistas. Reforçamos que a ideia de direitos humanos contrahegemônicos está relacionada às lutas contra o sofrimento humano em sua amplitude, incluindo a natureza como parte da humanidade (p. 111), onde se encaixa muitas teologias progressistas.

Nesta reelaboração, o autor afirma que o sujeito humano é igualmente indivíduo e um ser coletivo, isto o capacita para o envolvimento em lutas e contestações. As lutas contra as injustiças e em prol da libertação e autonomia dos povos incluem Deus como provedor dessa liberdade e autonomia, sem diminuir ou eliminar o papel dos sujeitos na contestação da opressão e das injustiças. Ao citar o teólogo Johann Mertz, que afirma ser Deus um deus de escravos e não de conquistadores, Santos diz que estar na presença de Deus é estar presente nessas lutas (p. 115). Nesta articulação entre coletivo e individual, há também teologias islâmicas engajadas na luta pelos direitos das mulheres.

Se Deus está envolvido nas lutas contra a opressão dos povos, como concebem as teologias progressista, vide as várias teologias da libertação, estas contribuem sem dúvida para "ajudar as pessoas e os grupos sociais a mudar os valores e as relações sociais e políticas existentes" (p. 124). Neste sentido, o que o autor aponta como "sofrimento da carne" dos povos oprimidos não é enfrentado somente com gestos assistenciais, mas na interface destes com a luta política que intervenham nas causas do sofrimento humano, este é um trabalho para nós humanos. 
É no diálogo inter-religioso que encontramos um potencial para a interculturalidade no domínio da religião. A concepção intercultural dos direitos humanos de que fala Santos tem como base este diálogo a partir das narrativas que podem ser partilhadas criando um senso de comunidade "indiferentes à diversidade cultural [..] (p. 137). Estas narrativas substituem formulações conceituais que podem ser menos inteligíveis às culturas e pouco usuais em termos de diálogo.

Finalmente, é preciso desmistificar a ideia ocidental de distinção entre material e espiritual contestada por algumas pesquisas realizadas no continente africano. Como uma moeda que tem duas faces inseparáveis, assim é vista a relação entre dimensão material e espiritual. Portanto, as lutas contra-hegemônicas e os direitos humanos reelaborados nas zonas de contado com as teologias políticas não podem deixar de considerar que as lutas contra as injustiças sociais são por extensão parte de um projeto que também é divino.

A religião institucionalizada foi de algum modo impedida de participar das críticas anticapitalistas e anticoloniais durante muito tempo, seja por ter se associado as estruturas dominantes, seja por ter sido relegada ao espaço privado. Esse movimento impediu que "as forças motivadoras contidas na espiritualidade" (p. 141) da religião bloqueassem os indivíduos para um engajamento social terreno priorizando uma pátria celeste. Neste sentido, as teologias plurais progressistas podem fornecer uma espiritualidade que reforcem a necessidade urgente das lutas sociais contra a opressão dos povos e culturas ao redor do mundo. Como exemplo de mobilização desse tipo o autor aponta as comunidades eclesiais de base na América Latina.

Em síntese, a ideia do livro é enfatizar que as religiões têm potencial para desenvolver teologias progressistas que sirvam de base para as lutas contra-hegemônicas contra a globalização neoliberal. A proposta lançada pelo autor é a concepção de uma teologia intercultural que critica "as assimetrias epistemológicas resultante da globalização neoliberal e da primazia concedida ao conhecimento científico-técnico ocidental" (p. 50) e baseada em pensamentos que primam pelas lutas contra as injustiças e a favor da emancipação dos povos. Desta maneira, Deus como ativista dos direitos humanos seria contrário as diferentes formas de opressão pelas quais passam vários povos e culturas nas diferentes regiões do planeta. 


\section{Referências}

SANTOS, B. S. Se Deus fosse um ativista dos direitos humanos. São Paulo: Cortez, 2014.

CV E NOTA BIOGRÁFICA. Disponível em: <http://www.boaventuradeSantossantos.pt/pages/pt/cv-e-notabiografica.php>. Acesso em: 03 jan. 2017.

Recebido em 01/08/2016

Aprovado em 27/12/2016 